\title{
Synthesis of novel pregnane-based 20-carboxamides via palladium-catalysed aminocarbonylation
}

\author{
Gábor Mikle $^{1} \cdot$ Alexandra Zugó $^{1} \cdot$ Erzsébet Szatnik $^{1} \cdot$ Anita Maxim $^{1} \cdot$ Sándor Mahó $^{2} \cdot$ László Kollár $^{1,3}$
}

Received: 22 July 2020 / Accepted: 16 December 2020 / Published online: 4 January 2021

(c) The Author(s) 2020

\begin{abstract}
20-Carboxamidopregnene derivatives, such as 3 $\beta$-acetoxy-5 $\alpha$-pregn-20-ene-20-carboxamides and 5 $\alpha$-pregn-20-ene-20carboxamides were synthesized from the widely accessible 3 $\beta$-acetoxy-pregn-5,16-dien-20-one (PDA) using selective hydrogenation, hydrazine and iodoalkene formation, as well as palladium-catalysed aminocarbonylation. The 20-iodo-20-ene derivatives, obtained from the corresponding 20-keto derivatives via their hydrazones, served as substrates. 23 new 20-carboxamides were obtained using various $N$-nucleophiles ranging from simple primary amines to $\alpha$-amino acid esters. The novelty of this methodology lies in the application of facile, moderate or high-yielding reactions to obtain otherwise hardly accessible steroidal 20-carboxamides of pharmaceutical importance. In other words, instead of the enzymatic or synthetic degradation of e.g., sterols or cholanic acids, functionalization of the basic skeleton (a 'building-up' approach) was used.
\end{abstract}

Keywords Iodoalkene $\cdot$ Carboxamide $\cdot$ Pregnane $\cdot$ Palladium $\cdot$ Aminocarbonylation

Supplementary Information The online version contains supplementary material available at https://doi.org/10.1007/s1169 6-020-01478-7.

László Kollár

kollar@gamma.ttk.pte.hu

Gábor Mikle

miklegabor8@gmail.com

Alexandra Zugó

zugo.alexandra@gmail.com

Erzsébet Szatnik

szatnikerzsebet@gmail.com

Anita Maxim

maximanita@gmail.com

Sándor Mahó

s.maho@richter.hu

1 Department of Inorganic Chemistry, Faculty of Sciences, University of Pécs, Ifjúság 6, Pecs 7624, Hungary

2 Chemical Works of Gedeon Richter Plc., Budapest, Hungary

3 János Szentágothai Research Center and MTA-PTE Research Group for Selective Chemical Syntheses, Ifjúság u. 6., Pecs 7624, Hungary

\section{Introduction}

The efficiency of homogeneous catalytic reactions, due to their high activity, as well as chemo-, regio- and enantioselectivity is well known. In the last decades the highly selective hydrogenation, isomerization, various carbonylation and cross-coupling reactions, catalysed by various transition metal complexes, have become important tools of the synthetic chemist.

Among the homogeneous catalytic functionalization of various skeletons of practical importance (Cornils et al. 1996; Beller et al. 1998; Omae 1998), that of the steroidal backbone is of primary interest (Skoda-Földes et al. 2003). A great variety of transition metal-catalysed reactions, for instance alkene and carbonyl hydrogenations, various carbonylations and coupling reactions were used to introduce new functionalities. Among these reactions, the synthesis of carboxamides via palladium-catalysed aminocarbonylation is one of the most promising one. Several families of these steroid-based carboxamides possess $5 a$-reductase inhibitor properties (see below).

The synthesis of carboxamides from easily available iodoaromatics (or aryl triflates, their synthetic surrogates) is a straightforward methodology. The seminal work of Heck et al. ('Heck-carbonylation') (Schoenberg and Heck 1974a, b, Schoenberg et al. 1974) provided a solid 
basis for the homogeneous catalytic functionalization of the above substrates. Several reviews and book chapters have been published on the aminocarbonylation of aryl halides (Roy et al. 2012; Wu et al. 2011, 2013; Magano and Dunetz 2011; Grigg and Mutton 2010; Barnard 2008; Skoda-Földes et al. 2002; Gadge and Bhanage 2014). Even the importance of the double carbon monoxide insertion resulting in 2-ketocarboxamides (Ozawa et al. 1984; Son et al. 1988) has been emphasised, i.e., the chemoselectivity towards 2-ketocarboxamides/carboxamides is an important issue. However, the aminocarbonylation of iodoalkenes/ enol triflates is a chemoselective reaction providing unsaturated carboxamides only (Kiss et al. 2015). The double carbon monoxide insertion, i.e., the formation of unsaturated ketocarboxamides requires special triarylphosphitebased palladium catalysts (Carrilho et al. 2012).

The introduction of an amide functionality in steroidal substrates via palladium-catalysed aminocarbonylation, especially into the most distinguished position-3 and -17 (in ring $\mathrm{A}$ and $\mathrm{D}$, respectively), has long been the aim of the patent literature as well (Holt et al. 1989, 1990; Cacchi et al. 1986; Dolle et al. 1987; Tian et al. 2000; McGuire et al. 1998; Petz et al. 2001). Efforts have been made also for the synthesis of 11- and 12-carboxamides using the same methodology, i.e., aminocarbonylation of the corresponding iodoalkene functionalities in the most hindered positions (Ács et al. 2006, 2007). Although the pharmacological importance such as inhibition of concise enzymes in ergosterol biosynthesis (Müller et al. 2015), anti-inflammatory (Kim et al. 1987), 24-methyl transferase (Lorente et al. 2005) and anti-microbial activities (Khabnadideh et al. 2000) of 20-carboxamides have been reported, to the best of our knowledge, only cholenic acid-based multistep procedures have been published for their synthesis. The procedure includes the activation of 20-acids as nitrophenol esters, followed by protection-deprotection sequence. Alternatively, ergosteryl acetate has been subjected to hydrogenation using Raney $\mathrm{Ni}$, and the 5 $\alpha, 6$-dihydroergosteryl acetate product has been oxidized to the corresponding acid using potassium permanganate. The acid chloride has been prepared by oxalyl chloride and reacted further with the corresponding primary or secondary amine (Giera et al. 2008).

Based on our preliminary investigations with similar iodoalkene functionalities, i.e., their use in aminocarbonylation/cyclization sequence to obtain oxazoles (Szuroczki et al. 2018), as well as in asymmetric aminocarbonylation to obtain diastereoisomers of various carboxamides (Mikle 2017), a systematic investigation regarding the structure of both substrate and $N$-nucleophile was decided. In the present paper, a facile procedure for the synthesis of 20-carboxamidopregnenes is described using the 20-keto-20-hydrazone-20-iodo-20-ene-20-carboxamido-20-ene reaction pathway.

\section{Experimental}

\section{Materials and equipment}

Celite ${ }^{\circledR}$, sodium hydroxide, iodine, $\mathrm{PPh}_{3}$, palladium(II) acetate, PDA (1) and Pd/C catalyst were purchased from Sigma-Aldrich. Commercial $\mathrm{Et}_{3} \mathrm{~N}$, primary and secondary amines including amino acid esters (Sigma-Aldrich) were used without further purification. Toluene and DMF were dried according to standard procedures; THF, ethyl acetate and ethanol were used without further purification.

The ${ }^{1} \mathrm{H}$ - and ${ }^{13} \mathrm{C}$-NMR spectra were recorded on a Bruker 500 spectrometer at 500 and $125.721 \mathrm{MHz}$, respectively. The chemical shifts are given as $\delta$ values (ppm) and referenced to tetramethylsilane. TLC analyses were carried out using Merck TLC sheets (Silica gel $60 \mathrm{~F}_{254}$ ) and chloroform, chloroform/ethyl acetate, and chloroform/methanol mixtures were used as appropriate eluents. (The exact ratios are given at the corresponding synthetic procedures.) Mass-spectrometry data have been obtained using a GC-MS system consisting of a Perkin Elmer AutoSystem XL gas-chromatograph and Perkin Elmer TurboMass mass spectrometer.

\section{Hydrogenation of 1 and 4}

The unsaturated steroid 3 $\beta$-acetoxy-pregn-5,16-diene-20one ('PDA') (1) (or in the analogous procedure, 4) (20 g, $56.1 \mathrm{mmol})$ was dissolved in ethyl acetate $(120 \mathrm{~mL})$ under argon in a $500 \mathrm{~mL}$ three-necked flask equipped with a gas inlet, reflux condenser with a balloon at the top. A suspension of $605 \mathrm{mg}$ of $\mathrm{Pd} / \mathrm{C}(5 \%)$ (or $605 \mathrm{mg}$ of $\mathrm{Pd} / \mathrm{C}(10 \%)$ ) in ethyl acetate $(20 \mathrm{~mL})$ was added to the stirred solution at room temperature, then the atmosphere was changed to $\mathrm{H}_{2}$ (1 bar). The composition of the reaction mixture was checked by GC. After completion of the reaction, the mixture was filtered on Celite ${ }^{\circledR}$. The solvent was removed and the product was recrystallized from ethyl acetate. Yield: 2: $18.04 \mathrm{~g} \mathrm{(90 \% )} \mathrm{(when} \mathrm{Pd/C} \mathrm{(5 \% )} \mathrm{was} \mathrm{used);} \mathrm{3:} 17.3 \mathrm{~g} \mathrm{(85 \% )}$ (when Pd/C (10\%) was used).

\section{Synthesis of 4 via hydrolysis and water elimination}

The compound saturated in both 5-ene and 16-ene positions (3) $(8.5 \mathrm{~g}, 23.67 \mathrm{mmol})$ was dissolved in $240 \mathrm{~mL}$ of ethanol and $10 \% \mathrm{NaOH}$ solution $(6.3 \mathrm{~mL})$ was added. The reaction mixture was heated for $2 \mathrm{~h}$ at $100{ }^{\circ} \mathrm{C}$ then concentrated under reduced pressure. Coldwater $(200 \mathrm{~mL})$ and $10 \% \mathrm{HCl}$ solution $(20 \mathrm{~mL})$ were added. The steroid was filtered and washed with water to neutral $\mathrm{pH}$, and dried.

The hydrolysed steroid $(7.3 \mathrm{~g}, 22.92 \mathrm{mmol}), p$-toluenesulfonic acid monohydrate $(1.75 \mathrm{~g}, 9.22 \mathrm{mmol})$ and silica 
gel $(52.64 \mathrm{~g})$ were dissolved in toluene $(460 \mathrm{~mL})$ and stirred at $120{ }^{\circ} \mathrm{C}$ for $5 \mathrm{~h}$. The composition of the reaction mixture was checked by GC. After the reaction was completed, the silica was filtered off, washed with toluene $(1000 \mathrm{~mL})$ and the solvent was evaporated. Yield: $4.82 \mathrm{~g}(70 \%)$.

\section{Synthesis of 20-iodo-3 $\beta$-acetoxy-5a-pregn-20-ene (8) and 20-iodo-5a-pregn-20-ene (9)}

$3 \beta$-Acetoxy-pregn-5-ene-20-one (2) or 5 $\alpha$-pregnan-20-one (5) $(14 \mathrm{mmol})$, hydrazine hydrate $(15.2 \mathrm{~mL}, 314 \mathrm{mmol})$ and triethylamine $(7.8 \mathrm{~mL}, 55.8 \mathrm{mmol})$ in ethanol $(42 \mathrm{~mL})$ were stirred for $2.5 \mathrm{~h}$ at $100{ }^{\circ} \mathrm{C}$ under argon. After cooling, removal of the solvent resulted in some crystal formation. Coldwater $(100 \mathrm{~mL})$ was added to the mixture. The precipitated material was filtered and washed with water to neutral $\mathrm{pH}$. The white crystalline hydrazone $(\mathbf{6}, \mathbf{7})$ was dried to constant weight under vacuum.

The hydrazone (6) (or 7) $(13.46 \mathrm{mmol})$ and triethylamine $(18.8 \mathrm{~mL}, 134.6 \mathrm{mmol})$ were dissolved in THF $(87 \mathrm{~mL})$ under argon in a $500 \mathrm{~mL}$ three-necked flask. A solution of iodine $(6.84 \mathrm{~g}, 26.92 \mathrm{mmol})$ in THF $(26 \mathrm{~mL})$ was added dropwise to the stirred solution. After the addition was completed, the mixture was stirred for $1 \mathrm{~h}$. The amine salt was filtered and the mixture was poured dropwise into a stirred solution of $\mathrm{Na}_{2} \mathrm{~S}_{2} \mathrm{O}_{5}(7.06 \mathrm{~g}, 37.14 \mathrm{mmol})$ in water $(1000 \mathrm{~mL})$. The precipitated steroid was filtered and washed with water to neutral $\mathrm{pH}$ and dried under vacuum. The steroidal iodoalkene was recrystallized from aqueous ethanol.

\section{General procedure for aminocarbonylation}

A steroidal iodoalkene substrate 8 (or 9) $(1 \mathrm{mmol}$ ), palladium(II) acetate $(5.6 \mathrm{mg}, 0.025 \mathrm{mmol})$, and $\mathrm{PPh}_{3}$ (13.1 mg, $0.05 \mathrm{mmol}$ ) were dissolved in $10 \mathrm{~mL} \mathrm{DMF}$ under argon. Triethylamine $(0.5 \mathrm{ml})$ and tert-butylamine (a) $(0.525 \mathrm{~mL} 5 \mathrm{mmol})$ [or another $N$-nucleophile $1.5 \mathrm{mmol}$ (b-e)] were added. (The amino acid methyl esters (f-k) were used as hydrochloride salts $(1.1 \mathrm{mmol})$ and were added together with the catalyst.) The atmosphere was changed to $\mathrm{CO}(1 \mathrm{bar})$, and the reaction was conducted at $50{ }^{\circ} \mathrm{C}$ for the appropriate reaction time. The composition of the reaction mixture was checked by GC. The solvent was evaporated, and the residue was dissolved in $20 \mathrm{~mL}$ of $\mathrm{CHCl}_{3}$. It was washed in turn with $20 \mathrm{~mL}$ of water, $20 \mathrm{~mL}$ portions of $5 \% \mathrm{HCl}$, saturated $\mathrm{NaHCO}_{3}$, and brine. The organic layer was separated, dried over $\mathrm{Na}_{2} \mathrm{SO}_{4}$ and evaporated. Column chromatography (silica gel, 95/5 $\mathrm{CHCl}_{3} / \mathrm{MeOH}, 100 / 0,95 / 5$, 90/10, 80/20, or 50/50 $\mathrm{CHCl}_{3} / \mathrm{EtOAc}$; the exact composition of the eluents are given in Supporting Material) resulted in the target 20-carboxamido-20-ene derivatives (10a-k, 11a-l).

\section{Results and discussion}

\section{Synthesis of 20-iodo-20-ene derivatives from PDA}

According to a retrosynthetic analysis (Scheme 1), to synthesize steroids with carboxamido functionality at the position-20, pregnene derivatives possessing the 20-iodo/ trifiloxy-20-ene moieties have to be obtained. To achieve this goal, one of the most efficient ways could be the synthesis of the corresponding 20-keto derivatives. In contrary to previous approaches based on the degradation of sterols (for instance Giera et al. 2008), our methodology is aimed at using functionalization of a pregnane skeleton. Although the oxidative degradation approach, i.e., the oxidation of the $\mathrm{C}_{8}-\mathrm{C}_{10}$ alkenyl chains bound to 17-position, has been used to obtain pregnane- and androstane-based compounds for a long time (Giera et al. 2008, Fried et al. 1972), the high chemoselectivity (practically no steroidal side products) and the simple protocol encouraged us to follow the 'bottomup' approach based on 20-keto derivatives. Furthermore, the synthesis is based on the application of simple 'small molecules', such as carbon monoxide and primary and secondary amines as building blocks.

$3 \beta$-Acetoxy-pregn-5,16-diene-20-one (pregna-5,16-

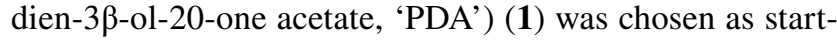
ing material. Its heterogeneous catalytic hydrogenation (Scheme 2) leads to the partially and fully hydrogenated compounds, 2 and 3 (Shingate et al. 2007), respectively. The hydrogenation of the double bonds proceeds in a consecutive manner, therefore, both compounds ( $\mathbf{2}$ and $\mathbf{3}$ ) possessing the required 20-keto functionalities can be obtained
Scheme 1 Retrosynthetic analysis of the synthesis of steroidal 20-carboxamides. (R, R': H, alkyl, aryl; X: I, OTf)

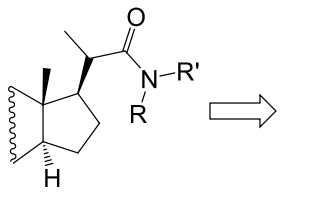

$\mathrm{HNRR}^{\prime}+\mathrm{C}_{2} \mathrm{O}_{2} \mathrm{Cl}_{2}+{ }_{\text {咅 }}^{\mathrm{COOH}} \longrightarrow$
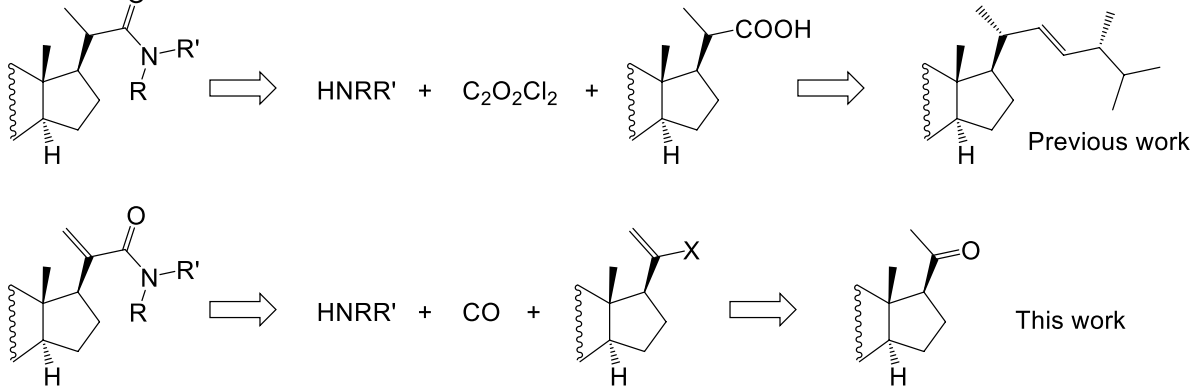

$\mathrm{HNRR}^{\prime}+\mathrm{CO}+\sum_{\mathrm{H}} \longrightarrow$
This work 
as analytically pure compound. The hydrogenation of both 16-ene and 5-ene double bonds are highly stereoselective: $17 \alpha-\mathrm{H}$ and $5 \alpha-\mathrm{H}$ epimers were obtained with high selectivity. As expected, heterogeneous hydrogenation takes place preferably from the $\alpha$-side.

To synthesize a model compound without $3 \beta$-acetoxy functionality, two pathways were chosen: (1) acetic acid was eliminated from compound $\mathbf{1}$, and the resulting mixture of dienes (3,5-diene and 2,4-diene) was hydrogenated to the hardly separable mixture of the two epimers ( $5 \alpha$ and $5 \beta$-prenan-20-one formed mainly from 3,5-diene and 2,4-diene, respectively); (2) the pure $5 \alpha$-epimer (3) was subjected to acetate hydrolysis and elimination of water (D'Onofrio and Scettri 1985), and the hydrogenation of the mixture of 2-ene and 3-ene (4) resulted in the formation of 5 (Scheme 3). Since the first methodology proved to be not feasible, in further syntheses, the latter method, resulting in practically epimerically pure product (5) was applied.
The 20-iodo-20-ene substrates $\mathbf{8}$ and $\mathbf{9}$ were synthesised from the corresponding ketones ( 2 and $\mathbf{5}$ ) via their hydrazones (6 and 7, respectively), using the modified Barton's method (Scheme 4) (Barton et al. 1962, 1983, Krubine et al. 1969).

\section{Synthesis of 20-carboxamido-20-enes via palladium-catalysed aminocarbonylation}

The iodoalkenes 8 and $\mathbf{9}$ were reacted as substrates in palladium-catalysed aminocarbonylation reaction (Scheme 5). Various primary and secondary amines were used as $N$-nucleophiles (tert-butylamine (a), aniline (b), benzylamine (c), piperidine (d), morpholine (e), methyl glycinate (f), methyl alaninate $(\mathbf{g})$, methyl serinate $(\mathbf{h})$, methyl valinate (i), methyl phenylalaninate (j), methyl prolinate (k)) and $\alpha$-phenylethylamine (l) in DMF under atmospheric carbon monoxide in the presence of

Scheme 2 Hydrogenation of 1

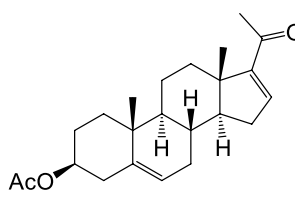

1

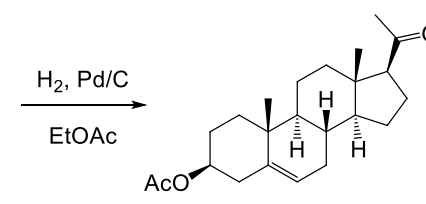

$2(90 \%)$<smiles>CCOC(C)=O</smiles>

Scheme 3 The synthesis of $5 \alpha$-pregnan-20-one (5)

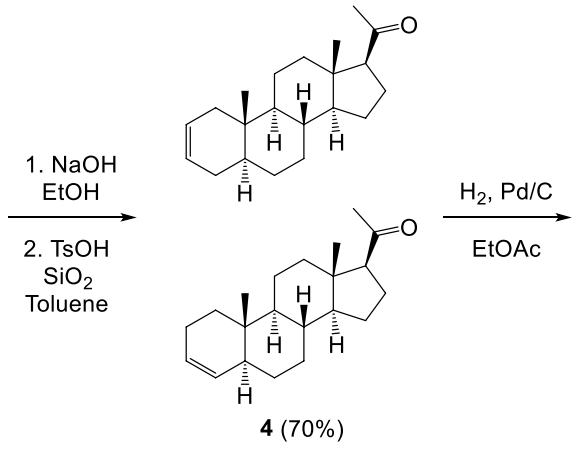

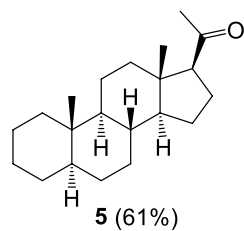

Scheme 4 Synthesis of 20-iodo-20-ene derivatives ( $\mathbf{8}$,

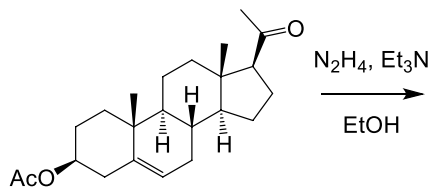

2

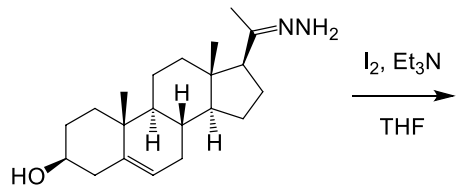

$6(89 \%)$<smiles>C=C(I)C1CCC2C3CC4=CC(O)CCC4(C)[C@H]3CC[C@@]12C</smiles>

$8(50 \%)$
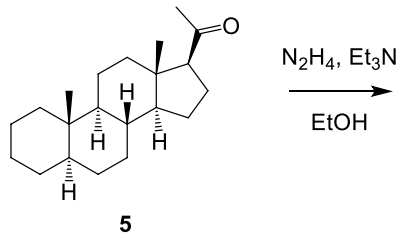

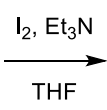

$7(97 \%)$

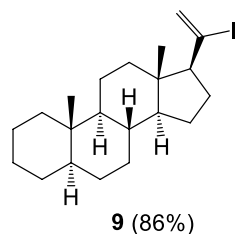




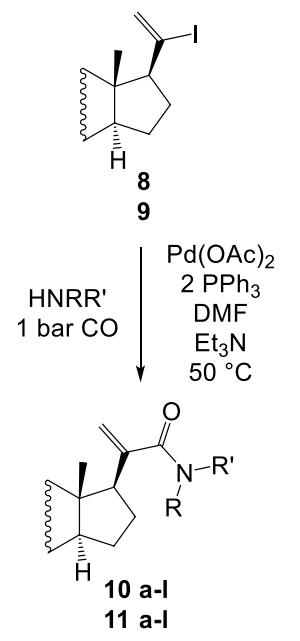

\begin{tabular}{lll} 
& $\mathrm{R}$ & $\mathrm{R}^{\prime}$ \\
a) & $\mathrm{H}$ & ${ }^{t} \mathrm{Bu}$ \\
b) & $\mathrm{H}$ & $\mathrm{Ph}$ \\
c) & $\mathrm{H}$ & $\mathrm{CH}_{2} \mathrm{Ph}$ \\
d) & \multicolumn{2}{c}{$-\left(\mathrm{CH}_{2}\right)_{5^{-}}$} \\
e) & $-\left(\mathrm{CH}_{2}\right)_{2}-\mathrm{O}^{-}\left(\mathrm{CH}_{2}\right)_{2}^{-}$ \\
f) & $\mathrm{H}$ & $\mathrm{CH}_{2} \mathrm{COOCH}_{3}$ \\
g) & $\mathrm{H}$ & $\mathrm{CH}\left(\mathrm{CH}_{3}\right) \mathrm{COOCH}_{3}$ \\
h) & $\mathrm{H}$ & $\mathrm{CH}\left(\mathrm{CH}_{2} \mathrm{OH}\right) \mathrm{COOCH}_{3}$ \\
i) & $\mathrm{H}$ & $\mathrm{CH}\left(\mathrm{CH}_{(}\left(\mathrm{CH}_{3}\right)_{2}\right) \mathrm{COOCH}_{3}$ \\
j) & $\mathrm{H}$ & $\mathrm{CH}\left(\mathrm{CH}_{2} \mathrm{Ph}\right) \mathrm{COOCH}_{3}$ \\
k) & $-\mathrm{CH}\left(\mathrm{COOCH}_{3}\right)\left(\mathrm{CH}_{2}\right)_{3}^{-}$ \\
l) & $\mathrm{H}$ & $\mathrm{CH}\left(\mathrm{CH}_{3}\right) \mathrm{Ph}$
\end{tabular}

Scheme 5 Aminocarbonylation of iodoalkenes $(\mathbf{8}, \mathbf{9})$ toward 20-carboxamides $(\mathbf{1 0}, \mathbf{1 1})$

palladium(0)-triphenylphosphine catalysts formed in situ. Palladium(II) acetate was used as a catalytic precursor.

The formation of highly active coordinatively unsaturated $\operatorname{Pd}(0)$ species was investigated by cyclic voltammetry and NMR techniques in the presence of mono- and bidentate phosphines (Csákai et al. 1999, Amatore et al. 1992, 1995). It has to be noted that triphenylphosphine was used only in a twofold excess to palladium. One equivalent is responsible for the reduction of $\operatorname{Pd}(\mathrm{II})$ to $\operatorname{Pd}(0)$ while it is oxidised to triphenylphosphine oxide.

The resulting $\operatorname{Pd}(0)$ intermediate is a highly reactive, lowligated intermediate which is apt to activate the iodoalkenyl substrates $(\mathbf{8}, 9)$ in oxidative addition. This type of catalytic system proved to be efficient also in further steps of the catalytic cycle such as carbon monoxide activation, its insertion into the alkenyl-palladium bond, amine activation, as well as reductive elimination in the product-forming step (Table 1).

The iodoalkene functionality (20-iodo-20-ene) reacted selectively and quantitatively toward the corresponding 20-carboxamido-21-ene derivatives (10a-k, 11a-l) under mild conditions (atmospheric $\mathrm{CO}$ pressure, $50{ }^{\circ} \mathrm{C}$ ). As expected, practically no influence of the structure of the A-ring on conversion and isolated yields was observed. That is, the removal of $3 \beta$-hydroxy functionality has no measurable effect on the reactivity of the 20-iodo-20-ene moiety.

However, the structure of the amine nucleophile has some effect on the conversion. In general, $1-1.5 \mathrm{~h}$ are needed to achieve close to complete conversion ('GC-yields' higher than $98 \%$ ). In the case of $\mathbf{b}, \mathbf{d}, \mathbf{e}$ and $\mathbf{k}$ nucleophiles $3 \mathrm{~h}, 5 \mathrm{~h}$, $4.5 \mathrm{~h}$ and $4 \mathrm{~h}$ reaction times were requested, respectively. The low reactivity of the less basic aromatic amine (b) is not surprising in the light of earlier results obtained with a great variety of iodoalkenes. In general, the secondary amines, especially $\mathbf{k}$ show lower reactivity than the primary
Table 1 Isolated yields of 20-carboxamides (10a-l and 11 a-l $)^{\mathrm{a}}$

\begin{tabular}{|c|c|c|}
\hline$N$-nucl & $\begin{array}{l}\text { Products [ } \\
\text { yields, }(\%)\end{array}$ & solated \\
\hline $\mathrm{a}$ & $10 a(75)$ & $11 \mathbf{a}(52)$ \\
\hline $\mathrm{b}$ & $\mathbf{1 0 b}(51)$ & 11b (51) \\
\hline $\mathrm{c}$ & 10c (97) & 11c (51) \\
\hline d & $\operatorname{10d}(56)$ & $\operatorname{11d}(51)$ \\
\hline $\mathrm{e}$ & $\mathbf{1 0 e}(63)$ & $11 \mathrm{e}(53)$ \\
\hline $\mathrm{f}$ & $\mathbf{1 0 f}(49)$ & $11 f(39)$ \\
\hline $\mathrm{g}$ & $\mathbf{1 0 g}(43)$ & $11 g(41)$ \\
\hline $\mathrm{h}$ & 10h (59) & 11h $(54)$ \\
\hline $\mathrm{i}$ & 10i (33) & $11 \mathbf{i}(55)$ \\
\hline $\mathrm{j}$ & $\mathbf{1 0 j}(54)$ & $\mathbf{1 1} \mathbf{j}(51)$ \\
\hline $\mathrm{k}$ & 10k (59) & $11 \mathbf{k}(50)$ \\
\hline 1 & $101(92)^{b}$ & $111(75)$ \\
\hline
\end{tabular}

${ }^{\mathrm{a}}$ For reaction conditions see "General procedure for aminocarbonylation" (above)

${ }^{\text {b} M i k l e ~ e t ~ a l . ~} 2017$

amines (Schoenberg and Heck 1974a, b, Schoenberg et al. 1974, Skoda-Földes et al. 2002, Kiss et al. 2015). Using these steroidal iodoalkene substrates (20-iodo-20-pregnenes) this effect is even more pronounced.

As mentioned above, the reactions were conducted to almost complete conversion. In spite of that, the isolated yield of the target carboxamides can be considered as moderate only, due to the loss of products during chromatographic work-up of the catalytic reaction mixture. In this way, the isolated yields of the analytically pure products varied from 33 to $97 \%$. In general, the carboxamides $\mathbf{1 0}$ can be isolated in higher yields than carboxamides $\mathbf{1 1}$ (compare for instance 10a and 11a; 10c and 11c; 10e and 11e, etc.). As the only exception nucleophile $\mathbf{i}$ has to be mentioned, i.e., 11i was isolated in higher yield than $\mathbf{1 0 i}$.

\section{Conclusions}

In conclusion, it can be stated, that pregnane skeletons functionalised at 20-position can be synthesized in yields of practical interest in palladium-catalysed aminocarbonylation. 20-Iodo-20-ene functionality, easily accessible from 20 to one, provided a clean, high-yielding aminocarbonylation towards 20-carboxamido compounds. Although the reactivity of the amines depends on their basicity, even with less basic aromatic amines and more bulky ones isolated yields of practical importance can be obtained.

Acknowledgements This work was supported by the Hungarian Scientific Research Fund (OTKA K113177) and the GINOP-2.3.2-152016-00049 Grant. 
Funding Open access funding provided by University of Pécs.

\section{Compliance with ethical standards}

Conflict of interest On behalf of all authors, the corresponding author states that there is no conflict of interest.

Open Access This article is licensed under a Creative Commons Attribution 4.0 International License, which permits use, sharing, adaptation, distribution and reproduction in any medium or format, as long as you give appropriate credit to the original author(s) and the source, provide a link to the Creative Commons licence, and indicate if changes were made. The images or other third party material in this article are included in the article's Creative Commons licence, unless indicated otherwise in a credit line to the material. If material is not included in the article's Creative Commons licence and your intended use is not permitted by statutory regulation or exceeds the permitted use, you will need to obtain permission directly from the copyright holder. To view a copy of this licence, visit http://creativecommons.org/licenses/by/4.0/.

\section{References}

Ács P, Müller E, Czira G, Mahó S, Pereira M, Kollár L (2006) Facile synthesis of 12-carboxamido-11-spirostenes via palladium-catalyzed carbonylation reactions. Steroids 71:875-879. https://doi. org/10.1016/j.steroids.2006.05.019

Ács P, Jakab B, Takács A, Kollár L (2007) Facile synthesis of 11-carboxamido-androst-4,9(11)-dienes via palladium-catalyzed aminocarbonylation. Steroids 72:627-632. https://doi.org/10.1016/j. steroids.2007.04.004

Amatore C, Jutand A, M'Barki MA (1992) Evidence of the formation of zerovalent palladium from $\mathrm{Pd}(\mathrm{OAc})_{2}$ and triphenylphosphine. Organometallics 11:3009-3013. https://doi.org/10.1021/om000 $45 \mathrm{a} 012$

Amatore C, Carre E, Jutand A, M'Barki MA, Meyer G (1995) Evidence for the ligation of palladium $(0)$ complexes by acetate ions: consequences on the mechanism of their oxidative addition with phenyl iodide and $\mathrm{PhPd}(\mathrm{OAc})\left(\mathrm{PPh}_{3}\right)_{2}$ as intermediate in the heck reaction. Organometallics 14:5605-5614. https://doi.org/10.1021/ om00012a029

Barnard CFJ (2008) Palladium-catalyzed carbonylation-a reaction come of age. Organometallics 27:5402-5422. https://doi. org/10.1021/om800549q

Barton DHR, O'Brien RE, Sternhell S (1962) A new reaction of hydrazones. J Chem Soc. https://doi.org/10.1039/JR9620000470

Barton DHR, Bashiardes B, Fourrey JL (1983) An improved preparation of vinyl iodides. Tetrahedron Lett 24:1605-1608. https://doi. org/10.1016/S0040-4039(00)81721-9

Beller M, Bolm C (Eds.) (1998) Transition metals for organic synthesis (Vol. I-II.), Wiley-VCH, Weinheim

Cacchi S, Ciattini PG, Morera E, Ortar G (1986) Palladium-catalyzed carbonylation of aryl triplates. Synthesis of arenecarboxylic acid derivatives from phenols. Tetrahedron Lett 27:3931-3934. https ://doi.org/10.1016/S0040-4039(00)83920-9

Carrilho RM, Pereira MM, Takács A, Kollár L (2012) Systematic study on the catalytic synthesis of unsaturated 2-ketocarboxamides: palladium-catalyzed double carbonylation of 1-iodocyclohexene. Tetrahedron 68:204-207. https://doi.org/10.1016/j.tet.2011.10.065

Cornils B, Herrmann WA (eds) (1996) Applied homogeneous catalysis with organometallic compounds. Wiley-VCH, Weinheim

Csákai Z, Skoda-Földes R, Kollár L (1999) NMR investigation of $\mathrm{Pd}(\mathrm{II})-\mathrm{Pd}(0)$ reduction in the presence of mono- and ditertiary phosphines. Inorg Chim Acta 286:93-97. https://doi.org/10.1016/ S0020-1693(98)00366-1 (and references cited therein)

D'Onofrio F, Scettri A (1985) p-Toluenesulfonic acid adsorbed on silica gel: an efficient dehydrating agent of alcohols. Synthesis. https://doi.org/10.1055/s-1985-31463

Dolle RE, Schmidt SJ, Kruse LI (1987) Palladium catalysed alkoxycarbonylation of phenols to benzoate esters. J Chem Soc Chem Commun. https://doi.org/10.1039/C39870000904

Fried J, Edwards JA (Eds.) (1972) Organic reactions in steroid chemistry (Vol. I and II). Van Nostrand Reinhold Co., New York

Gadge ST, Bhanage BM (2014) Recent developments in palladium catalysed carbonylation reactions. RSC Adv 4:10367-10389. https ://doi.org/10.1039/C3RA46273K

Giera M, Renard D, Plössl F, Bracher F (2008) Lathosterol side chain amides - a new class of human lathosterol oxidase inhibitors. Steroids 73:299-308. https://doi.org/10.1016/j.steroids.2007.10.015

Grigg R, Mutton SP (2010) Pd-catalysed carbonylations: versatile technology for discovery and process chemists. Tetrahedron 66:5515-5548. https://doi.org/10.1016/j.tet.2010.03.090

Holt DA, Levy MA, Metcalf BW (1989) Smithkline Beecham Co.; EP. 0343954 A2, (Chem Abstr 1990, 112, 198890n)

Holt DA, Levy MA, Ladd DL, Oh H, Erb JM, Heaslip JI, Brandt M, Metcalf BW (1990) Steroidal A ring aryl carboxylic acids: a new class of steroid 5.alpha.-reductase inhibitors. J Med Chem 33:937-942. https://doi.org/10.1021/jm00165a009

Khabnadideh S, Tan CL, Croft SL, Kendrick H, Yardley V, Gilbert IH (2000) Squalamine analogues as potential anti-trypanosomal and anti-leishmanial compounds. Bioorg Med Chem Lett 10:1237-1239. https://doi.org/10.1016/S0960-894X(00)00196 $-7$

Kim PH, Bird J, Heiman AS, Hudson GF, Taraporewala IB, Lee HJ (1987) Synthesis of new antiinflammatory steroidal 20-carboxamides: (20R)- and (20S)-21-(N-substituted amino)-11.beta., 17,20-trihydroxy-3,21-dioxo-1,4-pregnadiene. J Med Chem 30:2239-2244. https://doi.org/10.1021/jm00395a011

Kiss M, Takács A, Kollár L (2015) Highly selective synthesis of carboxamides via transition metal catalysed aminocarbonylation. Curr Green Chem 2:319-338. https://doi.org/10.2174/22133 46102666150213212458

Krubiner AM, Gottfried N, Oliveto EP (1969) Synthesis of 17-deoxy$17 \alpha-$ and $-17 \alpha 20$-pregnynes and -20-pregnenes. J Org Chem 34:3502-3505. https://doi.org/10.1021/jo01263a061

Lorente SO, Jimenez CJ, Gros L, Yardley V, de Luca-Fradley K, Croft SL, Urbina JA, Ruiz-Perez LM, Pacanowska DG, Gilbert IH (2005) Preparation of transition-state analogues of sterol 24-methyl transferase as potential anti-parasitics. Bioorg Med Chem 13:5435-5453. https://doi.org/10.1016/j.bmc.2005.06.012

Magano J, Dunetz JR (2011) Large-scale applications of transition metal-catalyzed couplings for the synthesis of pharmaceuticals. Chem Rev 111:2177-2250. https://doi.org/10.1021/cr100346g

McGuire MA, Sorenson E, Klein DN, Baine NH (1998) Palladium and nickel catalyzed hydroxycarbonylation of a steroidal bromodiene in the synthesis of episteride, a potent $5 \alpha$-reductase inhibitor. Synth Commun 28:1611-1615. https://doi.org/10.1080/00397 919808006865

Mikle G, Boros B, Kollár L (2017) Asymmetric aminocarbonylaion of iodoalkenes in the presence of $\alpha$-phenylethylamine as an $N$-nucleophile. Tetrahedron Asymm 28:1733-1738. https://doi. org/10.1016/j.tetasy.2017.10.012

Müller Ch, Binder U, Maurer E, Grimm Ch, Giera M, Bracher F (2015) Fungal sterol C22-desaturase is not an antimycotic target as shown by selective inhibitors and testing on clinical isolates. Steroids 101:1-6. https://doi.org/10.1016/j.steroids.2015.05.004

Omae I (1998) Applications of organometallic compounds. Wiley, New York 
Ozawa F, Sugimoto T, Yamamoto T, Yamamoto A (1984) Preparation of trans- $\mathrm{Pd}(\mathrm{COCOR}) \mathrm{Cl}\left(\mathrm{PMePh}_{2}\right)_{2}$ complexes $(\mathrm{R}=\mathrm{Ph}$ and $\mathrm{Me})$ and their reactivities relative to double carbonylation promoted by palladium. Organometallics 3:692-697. https://doi.org/10.1021/ om00083a008

Petz A, Gálik G, Horváth J, Tuba Z, Berente Z, Pintér Z, Kollár L (2001) Facile, high-yielding synthesis of steroidal crown ethers via palladium-catalyzed carbonylation reaction. Synth Commun 31:335-341. https://doi.org/10.1081/SCC-100000521

Roy S, Roy S, Gribble GW (2012) Metal-catalyzed amidation. Tetrahedron 68:9867-9923. https://doi.org/10.1016/j.tet.2012.08.065

Schoenberg A, Heck RF (1974a) Palladium-catalyzed amidation of aryl, heterocyclic, and vinylic halides. J Org Chem 39:3327-3331. https://doi.org/10.1021/jo00937a004

Schoenberg A, Heck RF (1974b) Palladium-catalyzed formylation of aryl, heterocyclic, and vinylic halides. J Am Chem Soc 96:77617764. https://doi.org/10.1021/ja00832a024

Schoenberg A, Bartoletti I, Heck RF (1974) Palladium-catalyzed carboalkoxylation of aryl, benzyl, and vinylic halides. J Org Chem 39:3318-3326. https://doi.org/10.1021/jo00937a003

Shingate BB, Hazra BG, Pore VS, Gonnadeb RG, Bhadbhade MM (2007) Stereoselective syntheses of 20-epi cholanic acid derivatives from 16-dehydropregnenolone acetate. Tetrahedron 63:5622-5635. https://doi.org/10.1016/j.tet.2007.04.014

Skoda-Földes R, Kollár L (2002) Synthetic applications of palladium catalysed carbonylation of organic halides. Curr Org Chem 6:1097-1119. https://doi.org/10.2174/1385272023373699

Skoda-Földes R, Kollár L (2003) Transition-metal-catalyzed reactions in steroid synthesis. Chem Rev 103:4095-4129. https://doi. org/10.1021/cr020075g (and references cited therein)
Son T, Yanagihara H, Ozawa F, Yamamoto A (1988) Palladium-catalyzed double-carbonylation of alkenyl halides with secondary amines to give $\alpha$-keto amides. Bull Chem Soc Jpn 61:1251-1258. https://doi.org/10.1246/bcsj.61.1251

Szuroczki P, Mikle G, Kollár L (2018) Palladium-catalysed aminocarbonylation/cyclization of iodoalkenes toward $N$-propargylcarboxamides and oxazoles. Mol Catal 452:68-74. https://doi. org/10.1016/j.mcat.2018.03.015

Tian W, Lei Z, Chen L, Huang Y (2000) Some new reactions of poly(per)fluoroalk nesulfonyl fluorides with steroidal molecules. J Fluorine Chem 101:305-308. https://doi.org/10.1016/S0022 $-1139(99) 00175-X$

Wu XF, Neumann H, Beller M (2011) Palladium-catalyzed carbonylative coupling reactions between $\mathrm{Ar}-\mathrm{X}$ and carbon nucleophiles. Chem Soc Rev 40:4986-5009. https://doi.org/10.1039/C1CS1 $5109 \mathrm{~F}$

Wu XF, Neumann H, Beller M (2013) Synthesis of heterocycles via palladium-catalyzed carbonylations. Chem Rev 113:1-35. https ://doi.org/10.1021/cr300100s

Publisher's Note Springer Nature remains neutral with regard to jurisdictional claims in published maps and institutional affiliations. 